\title{
The increased cardiovascular risk in rheumatoid arthritis: when does it start?
}

\author{
Michael T Nurmohamed ${ }^{1,2,3 *}$ \\ See related research by Södergren et al., http://arthritis-research.com/content/12/4/R158
}

\begin{abstract}
Established rheumatoid arthritis (RA) is associated with a doubled cardiovascular risk. However, data about the cardiovascular risk in early RA are scarce. Preclinical atherosclerosis can be reliably assessed with the carotid intima media thickness (CIMT), and the CIMT is a wellvalidated predictor of cardiovascular events. The cIMT was therefore used in a recent controlled, prospective study in patients with early RA. Surprisingly, an increased cardiovascular risk at baseline could not be demonstrated whereas CIMT progression appeared to be comparable with the general population. Obviously, this study underscores the need for further large-scale investigations to solve the emerging discrepancy with the existing literature.
\end{abstract}

Nowadays it is well known that patients with established rheumatoid arthritis (RA) suffer from an increased cardiovascular risk in comparison with the general population, and both traditional cardiovascular risk factors as well as the underlying chronic inflammatory process contribute to this excess cardiovascular risk. Little is known, however, about the cardiovascular risk in early RA patients - hence the recent article by Södergren and colleagues could be an important contribution to the field [1].

The increased cardiovascular risk in RA is mainly due to atherosclerotic events. Until recently atherosclerosis was considered an accumulation of lipoproteins within the arterial wall. During the past decade, however, atherosclerosis has been recognized as a chronic inflammatory process in the artery. The first step in the process is endothelial dysfunction caused by traditional

*Correspondence: mt.nurmohamed@vumc.nl

'Department of Internal Medicine, VU University Medical Centre, De Boelelaan 1117, 1081 HV Amsterdam, The Netherlands

Full list of author information is available at the end of the article cardiovascular risk factors such as smoking. The endothelium becomes more permeable - to lipids, for example - and becomes procoagulant instead of anticoagulant. The inflammatory response further results in an entry of inflammatory cells and muscle cells. Foam cells are formed and result in fatty streaks. This lesion progresses and a fibrous cap is formed, consisting of smooth muscle cells and a collagen matrix that separates this atherosclerotic plaque from the arterial lumen. Ultimately, the plaque may rupture and the subsequent thrombosis causes a myocardial infarction.

In the study by Södergren and colleagues, the carotid intima media thickness (cIMT) (a marker of preclinical atherosclerosis) and flow-mediated dilatation of the brachial artery (a marker of endothelial dysfunction) were assessed in 79 early RA patients and in 44 agematched and sex-matched controls. In a subgroup of 27 RA patients (and controls), the assessments were repeated after 18 months. Carotid plaques, another feature of preclinical atherosclerosis that can be assessed during cIMT measurement, were not reported. The flowmediated dilatation and the cIMT at baseline were not significantly different between the two groups. This observation is remarkable particularly for the cIMT, as RA patients had significantly more cardiovascular risk factors (hypertension, smoking and dyslipidemia) important determinants of the cIMT [2] - than the controls, and one would expect at least a tendency for an increased cIMT in RA patients, whereas an opposite trend was seen. Moreover, these results contradict findings from other studies that indicate an increased rate of cardiovascular events as well as cardiovascular risk factors before the clinical onset of RA.

The cIMT thickness in both groups was, as expected, associated with the traditional cardiovascular risk factors, and no relationship with disease activity markers was found in the RA group. This latter finding is in line with the results of our recent meta-analysis of cIMT in established RA patients, where also no relationship with disease activity could be demonstrated [3]. Perhaps using a cumulative disease activity marker (for example, number of erosions) would have been more appropriate 
in view of the observed relationships between disease duration/severity and cardiovascular risk. Moreover, this meta-analysis revealed a cIMT difference of $0.09 \mathrm{~mm}$ between RA patients and controls, indicating an approximately $15 \%$ increased cardiovascular risk [4]. This value is far less than expected in view of the 50 to $100 \%$ increased cardiovascular risk demonstrated in early RA and established RA patients [5,6]. The majority of the cardiovascular events are caused by plaque ruptures, which must imply that plaques rupture earlier in an inflammatory situation than in a non-inflammatory situation [7].

The observed increase in cIMT for RA patients in the study by Södergren and colleagues was $0.05 \mathrm{~mm}$ in 18 months, and was significantly larger than that in the control group. This value fits within the increase observed in a much larger investigation in the general population [8], however, so it is tempting to speculate that this normal cIMT progression in RA patients was due to effective antirheumatic treatment, nowadays aimed at remission, even though prospective data about disease activity were not provided.

Although there remain some methodological issues, the study by Södergren and colleagues clearly underscores two pivotal aspects about the cardiovascular risk in RA: an increased prevalence of cardiovascular risk factors in RA, and that effective antirheumatic treatment probably decreases the cardiovascular risk in RA. Their study therefore supports the recently published European League Against Rheumatism recommendations for cardiovascular risk management in inflammatory arthritis patients, which advocate that cardiovascular risk management should be aimed at disease activity suppression as well as at cardiovascular risk factor screening and treatment [9].

As the present findings are in contradiction with the existing literature, larger prospective, controlled investigations with a rigorous methodological design are necessary. Another challenging topic for future studies is how to identify the patients with a high risk for plaque rupture. Such studies may hopefully become redundant when it is demonstrated that effective antirheumatic therapy, aimed at disease remission, normalizes the change of plaque rupture.

\section{Abbreviations}

CIMT, carotid intima media thickness; RA, rheumatoid arthritis.

\section{Author details}

'Department of Internal Medicine, VU University Medical Centre, De Boelelaan 1117, 1081 HV Amsterdam, The Netherlands. 'Department of Rheumatology, VU University Medical Centre, De Boelelaan 1117, 1081 HV Amsterdam, The Netherlands. ${ }^{3}$ Jan van Breemen Institute, Dr Jan van Breemenstraat 2, 1056 AB Amsterdam, The Netherlands.

\section{Competing interests}

The author declares that he has no competing interests.

Published: 29 September 2010

\section{References}

1. Södergren A, Karp K, Boman K, Eriksson C, Lundström E, Smedby T, Söderlund L, Rantapää-Dahlqvist S, Wållberg-Jonsson S: Atherosclerosis in early rheumatoid arthritis: very early endothelial activation and rapid progression of intima media thickness. Arthritis Res Ther 2010, 12:R158.

2. Michos ED, Rice KM, Szklo M, Burke GL, Siscovick DS, Tracy RP, Graham Barr R, Nettleton JA, Greenland P, Jacobs DR Jr, Post W: Factors associated with low levels of subclinical vascular disease in older adults: multi-ethnic study of atherosclerosis. Prev Cardiol 2009, 12:72-79.

3. van Sijl AM, Peters MJ, Knol DK, de Vet HC, Gonzalez-Gay MA, Smulders YM, Dijkmans BA, Nurmohamed MT: Carotid intima media thickness in rheumatoid arthritis as compared to control subjects: a meta-analysis. Semin Arthritis Rheum 2010, in press.

4. Bots ML, Hoes AW, Koudstaal PJ, Hofman A, Grobbee DE: Common carotid intima-media thickness and risk of stroke and myocardial infarction: the Rotterdam Study. Circulation 1997, 96:1432-1437.

5. Young A, Koduri G, Batley M, Kulinskaya E, Gough A, Norton S, Dixey J: Mortality in rheumatoid arthritis. Increased in the early course of disease, in ischaemic heart disease and in pulmonary fibrosis. Rheumatology (Oxford) 2007, 46:350-357.

6. Peters MJ, van Halm VP, Voskuyl AE, Smulders YM, Boers M, Lems WF, Visser M, Stehouwer CD, Dekker JM, Nijpels G, Heine R, Dijkmans BA, Nurmohamed MT: Does rheumatoid arthritis equal diabetes mellitus as an independent risk factor for cardiovascular disease? A prospective study. Arthritis Rheum 2009, 61:1571-1579.

7. Aubry MC, Maradit-Kremers H, Reinalda MS, Crowson CS, Edwards WD Gabriel SE: Differences in atherosclerotic coronary heart disease between subjects with and without rheumatoid arthritis. J Rheumatol 2007, 34:937-942.

8. Wagenknecht LE, Zaccaro D, Espeland MA, Karter AJ, O'Leary DH, Haffner SM: Diabetes and progression of carotid atherosclerosis: the insulin resistance atherosclerosis study. Arterioscler Thromb Vasc Biol 2003, 23:1035-1041.

9. Peters MJ, Symmons DP, McCarey D, Dijkmans BA, Nicola P, Kvien TK, Mclnnes IB, Haentzschel H, Gonzalez-Gay MA, Provan S, Semb A, Sidiropoulos P, Kitas G, Smulders YM, Soubrier M, Szekanecz Z, Sattar N, Nurmohamed MT: EULAR evidence-based recommendations for cardiovascular risk management in patients with rheumatoid arthritis and other forms of inflammatory arthritis. Ann Rheum Dis 2010, 69:325-331.

doi:10.1186/ar3126

Cite this article as: Nurmohamed MT: The increased cardiovascular risk in rheumatoid arthritis: when does it start? Arthritis Research \& Therapy 2010, 12:140. 